\title{
Heartbeat: Ischemic heart disease risk factors in women
}

Cardiovascular disease is the leading cause of death in women worldwide. Despite the known sex differences in clinical presentation, management and outcomes of patients with coronary heart disease (CHD), possible differences in primary and secondary prevention have received less attention. In this issue of Heart, Zhao and colleagues ${ }^{1}$ investigated sex differences in cardiovascular risk factor management in over 10 thousand patients $(29 \%$ women) from Europe, Asia and the Middle East. Compared with men, women had better blood pressure control and were more likely to be non-smokers. However, women were less likely to achieve medication targets for total cholesterol, low density lipoprotein cholesterol or serum glucose levels. In addition, women were more often obese and less physically active than men. Overall, lifestyle targets for cardiovascular risk reduction did not differ between women and men but women were about 25\% less likely to achieve medication treatment targets with marked geographic sex disparities for both lifestyle and medication treatment targets (figure 1).

In the accompanying editorial, $\mathrm{Al}$ Badri and colleagues ${ }^{2}$ comment that "The failure to receive evidence-based therapies in women is sadly a recurrent theme increasingly documented worldwide". They conclude that: "Knowledge gaps remain, which can be addressed by careful phenotyping of the increasingly available digital medical records and ambulatory monitoring technology, including proteomics, metabolomics, and genomics. Investigation addressing if large sex differences in risk factor management are due to lower treatment of women/higher treatment of men (USA and Europe), vs if lower sex differences are due to lower treatment of both women and men (Asia and Middle East). The need for country and region-specific IHD data stratified by sex is needed to optimise personalised medicine" (figure 2).

In a French study of 9012 men and women, age 50 to 75 years of age, Simon and colleagues ${ }^{3}$ found that $14.77 \%$ of women but only $6.84 \%$ of men met at

Correspondence to Professor Catherine M Otto, Division of Cardiology, University of Washington, Seattle, Washington, USA; cmotto@uw.edu

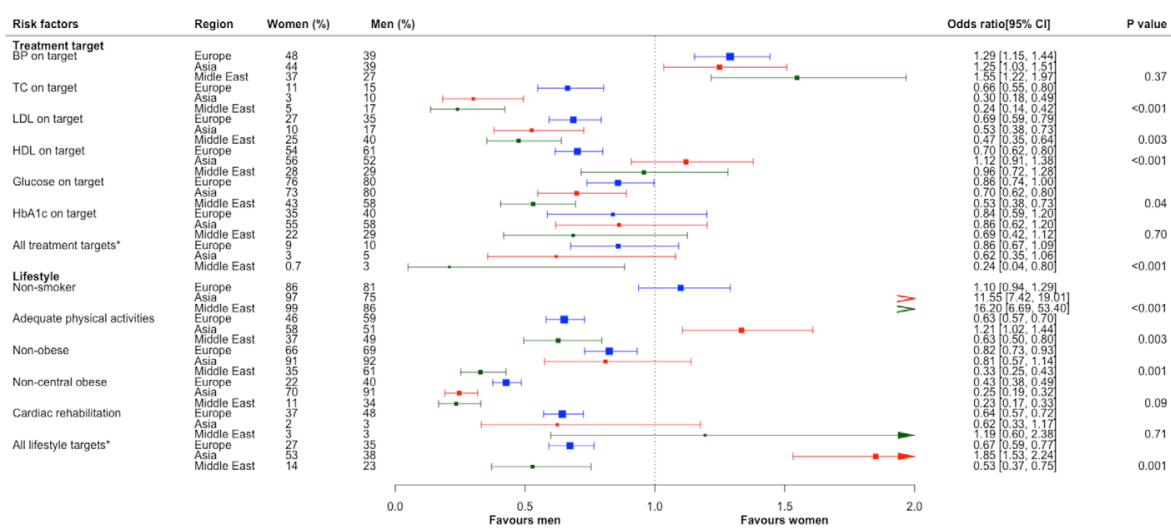

Figure 1 Age-adjusted sex differences on treatment targets and lifestyle factors management, stratified by region. Target blood pressure (BP) was defined as BP $<140 / 90 \mathrm{mmHg}$ in those without diabetes or $<140 / 80 \mathrm{mmHg}$ in those with diabetes. The target for total cholesterol (TC), low-density lipoprotein (LDL) cholesterol and high-density lipoprotein (HDL) cholesterol levels were defined as $<3 \mathrm{mmol} / \mathrm{L}$, $<1.8 \mathrm{mmol} / \mathrm{L}$, and $>1.0 \mathrm{mmol} / \mathrm{L}$ for men and $>1.2 \mathrm{mmol} / \mathrm{L}$ for women, respectively. Target glucose was defined as $<7 \mathrm{mmol} / \mathrm{L}$. Information on glycated haemoglobin (HbA1c) was only collected from patients with diabetes and its target was defined as $<7 \%$.

${ }^{*}$ Achieving all three medical targets (BP on target, LDL on target, and glucose/ $\mathrm{HbA} 1 \mathrm{c}$ on target) was defined as 'All treatment targets'. Obesity was defined as a body mass index (BMI) $\geq 30 \mathrm{~kg} /$ $\mathrm{m} 2$ and central obesity was defined as waist circumference $\geq 88 \mathrm{~cm}$ for women and $\geq 102 \mathrm{~cm}$ for men. Smoking status was current smoker and non-smoker. Adequate physical activity level was defined as moderate or vigorous physical activity for at least 30 min three or more times a week. * Reaching all three lifestyle targets (non-smoker, adequate physical activities, and nonobesity) was defined as 'All lifestyle targets'. Odds ratios $(95 \% \mathrm{Cl})$ presented as women versus men; $p$ values are for interaction between subgroups.

least 5 of the seven metrics defining ideal cardiovascular health. These metrics include ideal values for body mass index, smoking status, blood pressure, blood total cholesterol, blood glucose and physical activity. Women were slightly older, less educated, more often depressed and

more deprived than men; after adjustment for these factors women were four times more often in ideal cardiovascular heart than men (OR 4.01, 95\% CI 3.42 to 4.69$)$. These findings parallel the findings in Europeans in the study by Zhao and colleagues ${ }^{1}$ showing that risk factors

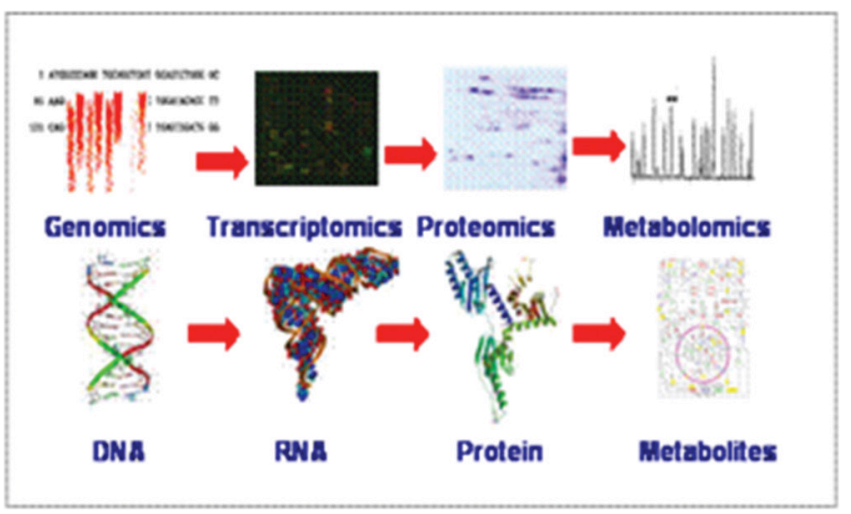

Figure 2 Sex-specific and gender-specific medicine is the most ready-for-translation approach among the genomic, proteomic, and metabolomic personalised medicine approaches. 

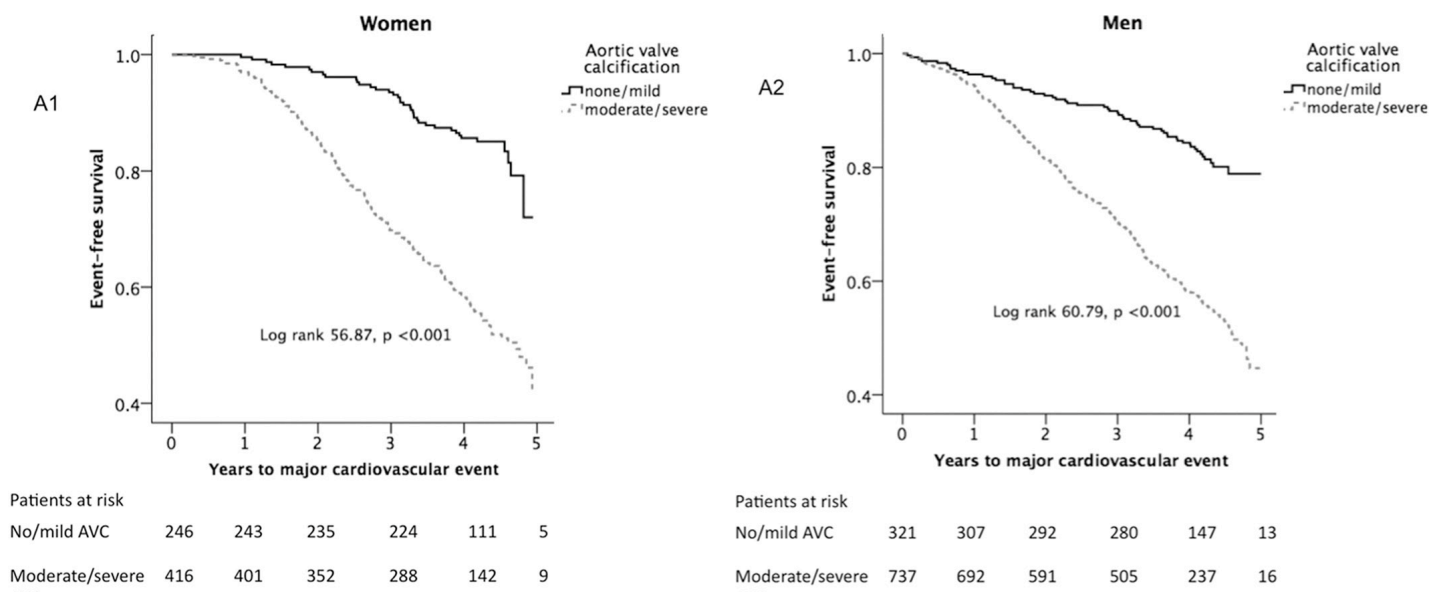

$\begin{array}{lllllll}\text { No/mild AVC } & 246 & 243 & 235 & 224 & 111 & 5 \\ \text { Moderate/severe } & 416 & 401 & 352 & 288 & 142 & 9\end{array}$ AVC
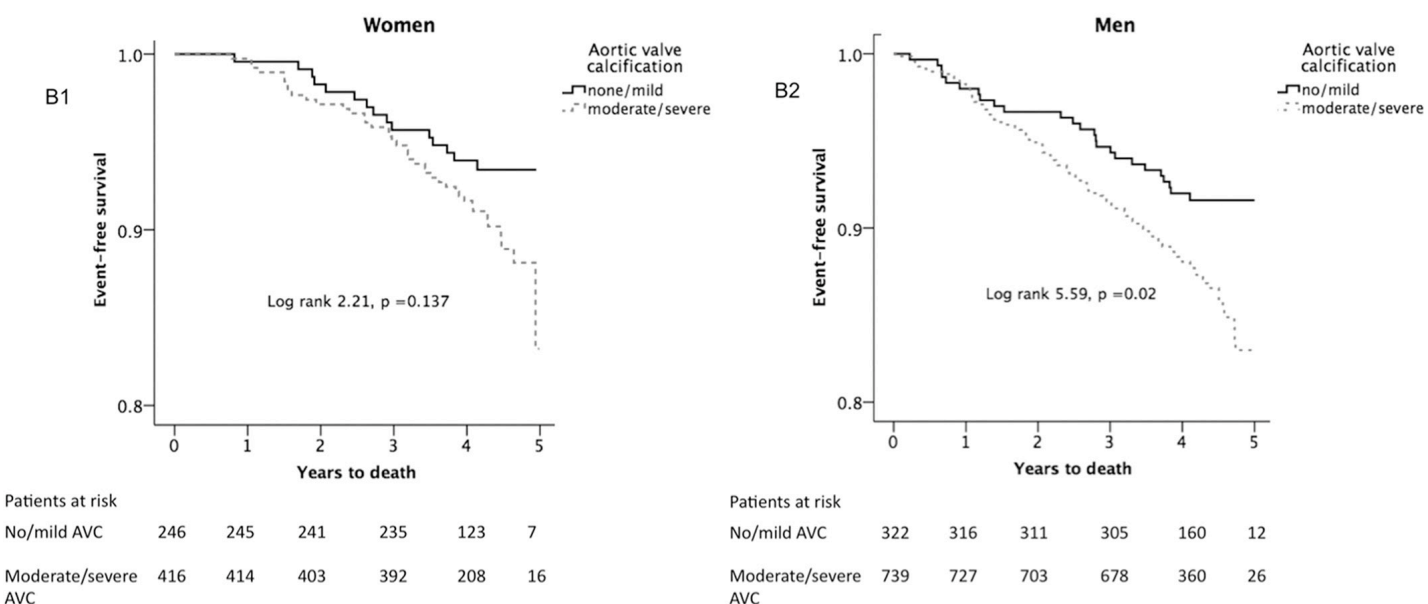

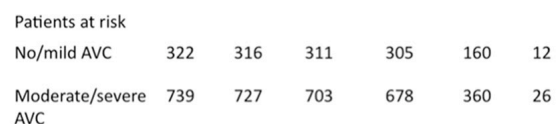

Figure 3 Kaplan-Meier curves reporting survival free of major cardiovascular events (A), and survival (B) in women (left panels) and men (right panels). AVC, aortic valve calcification.

for ischaemic disease are lower in European women compared with men; the exception is ideal cholesterol levels, which were less often achieved in women.
The authors conclude "it appears that behavioural cardiovascular heart needs to be particularly promoted in men, at least after 50 years of age". However, in my view the most remarkable finding in this study is how few women or men were in ideal cardiovascular health, only $7 \%$ to $15 \%$ overall. Clearly, our goal should be

Table 1 Sex-related differences in ACS presentation, outcomes and treatment strategy

\begin{tabular}{|c|c|c|c|}
\hline & Women & Men & $\mathrm{p}$ Value \\
\hline \multicolumn{4}{|l|}{ Clinical presentation } \\
\hline Age, mean (SD) & 71.2 years $^{48}$ & 63.4 years $^{48}$ & $<0.001$ \\
\hline Prehospital delay from symptom onset & $1.8-7.2$ hours $^{16}$ & $1.4-3.5$ hours $^{16}$ & \\
\hline Characteristics of symptoms & More likely to present with atypical symptoms* & More likely to present with chest pain ${ }^{17}$ & \\
\hline CAD in-hospital mortality rate $(\%)$ & $60.9-69.1^{49}$ & $58.6-67.2^{49}$ & $<0.001$ \\
\hline \multicolumn{4}{|l|}{ Pharmacotherapies administered } \\
\hline Aspirin (\%) & $87.5-92.7^{4875}$ & $90.4-94.7^{4875}$ & $<0.001$ \\
\hline Clopidogrel (\%) & $43.9-49^{4875}$ & $53.3-59^{4875}$ & $<0.001$ \\
\hline Beta-blockers (\%) & $66.8-80.5^{4875}$ & $72.6-82.7^{4875}$ & $<0.001$ \\
\hline ACE inhibitors/ARBs (\%) & $71^{77}$ & $75^{77}$ & $<0.001$ \\
\hline Lipid-lowering drugs (\%) & $55.9-65.8^{4875}$ & $69.4-75.3^{4875}$ & $<0.001$ \\
\hline $\begin{array}{l}\text { Periprocedural bleeding and vascular } \\
\text { complications }(\%)\end{array}$ & $4.7-5.4^{1970}$ & $1.7-2.7^{1970}$ & $<0.001$ \\
\hline $\mathrm{PCl}$ rate $(\%)$ & $33.3^{48}$ & $43.8^{48}$ & $<0.001$ \\
\hline CABG rate $(\%)$ & $47.6^{57}$ & $60.5^{57}$ & $<0.0001$ \\
\hline
\end{tabular}

References (numbered) can be found in the original article. ${ }^{6}$

*Including nausea/vomiting (OR 2.29,95\% Cl 1.19 to $4.42, \mathrm{p}=0.012)$, dyspnoea (OR $1.82,95 \% \mathrm{Cl} 1.05$ to $3.16, \mathrm{p}=0.032)$, palpitations (OR $3.42,95 \% \mathrm{Cl} 1.02$ to $11.47, \mathrm{p}=0.036)$ and abnormal pain location (OR $9.61,95 \% \mathrm{Cl} 1.19$ to $4.42, \mathrm{p}=0.012$ ).

ACS, acute coronary syndrome; ARBs, angiotensin II receptor blockers; CABG, coronary artery bypass grafting; CAD, coronary artery disease; PCI, percutaneous coronary intervention. 
to improve risk factor reduction in both men and women, particularly lifestyle factors such as an ideal body mass index and higher levels of physical activity.

Sex differences also are seen in men and women with calcific aortic valve disease. ${ }^{4}$ In the 1725 patients with asymptomatic aortic stenosis (AS) enrolled in the Simvastatin Ezetimibe in Aortic Stenosis study (SEAS), aortic valve calcification (AVC) was measured quantitatively by computed tomographic imaging. Interestingly, women had less AVC than men, even though AS was more severe based on haemodynamic criteria. In both men and women, moderate to severe calcification was associated with a higher hazard rate for major cardiovascular events, with a HR of 2.2 (men) to 2.5 (women) compared with no or mild AVC (figure 3 ).

In an editorial commenting on this study, Moura, Rocha-Gonçalves and Gavina ${ }^{5}$ raise a question: "The findings from this SEAS substudy underline the important pathophysiological differences between women and men and strongly support the development of future research in disease mechanisms specific to each sex and potential individualised interventions. But the question remains: Are we ready to introduce AVC in our recommendation for evaluation and management of patients in AS?" Further studies on this important issue are needed.

The Education in Heart article in this issue focuses on management of acute coronary syndromes (ACS) in women. ${ }^{6}$ Key points include the differences in presentation of ACS in women and the need for appropriate reperfusion therapy, as well as recognition of sex-related factors in women including pregnancy, menopause and an increased bleeding risk during percutaneous interventions. The authors also emphasise the need for guideline indicated secondary prevention and cardiac rehabilitation in women (table 1).

The Image Challenge question ${ }^{7}$ in this issue reminds us that women may present with an ACS that is not due to atherosclerotic vascular disease. This coronary angiogram is one that all of us should recognise and know how to treat, particularly in women.

\section{Competing interests None declared.}

Provenance and peer review Commissioned; internally peer reviewed.

(C) Article author(s) (or their employer(s) unless otherwise stated in the text of the article) 2017. All rights reserved. No commercial use is permitted unless otherwise expressly granted.

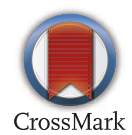

To cite Otto CM. Heart 2017;103:1559-1561.

Published Online First 28 September 2017

Heart 2017;103:1559-1561.

doi:10.1136/heartjnl-2017-312328

\section{REFERENCES}

1 Zhao M, Vaartjes I, Graham I, et al. Sex differences in risk factor management of coronary heart disease across three regions. Heart 2017;103:1587-94.

2 AlBadri A, Wei J, Merz NB, et al. Sex differences in coronary heart disease risk factors: rename it ischaemic heart disease!. Heart 2017;103:1567-8.

3 Simon M, Boutouyrie P, Narayanan K, et al. Sex disparities in ideal cardiovascular health. Heart 2017;103:1595-601.

4 Thomassen HK, Cioffi G, Gerdts E, et al. Echocardiographic aortic valve calcification and outcomes in women and men with aortic stenosis. Heart 2017; 103:1619-24.

5 Moura LM, Rocha-Gonçalves F, Gavina C. Is it time for sex-specific recommendations in aortic stenosis? Heart 2017;103:1565-6.

6 Madonis SM, Skelding KA, Roberts M. Management of acute coronary syndromes - special considerations in women. Heart 2017;103:1638-46.

7 Asher E, Kogan A, Segev A. Severe upper abdominal pain in a 43-year-old woman. Heart 2017;103:1650. 